\title{
Effect of Synoptic Scale Weather Disturbance to Philippine Transboundary Ozone Pollution using WRF-CHEM
}

\author{
Gerry Bagtasa
}

\begin{abstract}
Air pollution is not only caused by local emission but also by atmospheric pollutants being transported from the surrounding region. This study examines the impact of the downdraft at the edge of a long-lived typhoon system Parma on the transport of atmospheric pollution from the main Asian continent to the Philippines using the fully coupled Weather Research and Forecast - Chemistry (WRF-CHEM) regional air quality model. On the first week of October 2009, typhoon Parma became virtually stationary at the northern tip of the Philippines as it interacted with typhoon Melor via the Fujiwara effect, producing a rare northwest wind that provided a transport path for the pollutants. The simulation of Nitrogen Oxides (NOx: including $\mathrm{NO}$ and $\mathrm{NO}_{2}$ ) and Ozone $\left(\mathrm{O}_{3}\right)$ showed that gaseous NOx do not travel very far while the secondary pollutant $\mathrm{O}_{3}$ underwent long range transport.
\end{abstract}

Index Terms-Transboundary pollution, air quality modeling, tropospheric ozone, wrf-chem.

\section{INTRODUCTION}

Transport of atmospheric pollutants from regional to global scale is of significant concern due to consequences on human health, ecosystem, radiative forcing, hydrological cycle, oxidizing capacity of the troposphere, etc. [1]. Currently, anthropogenic emissions in Asia are larger than those in Europe and North America and is expected to continue to increase in the future [2]. One reason for this is China's rapid economic and industrial expansion over the last couple of decades, accompanied by tremendous increase in energy consumption as well as emission of atmospheric pollutants [3]. Despite this, the Philippines, unlike China's other east Asian neighbors, is rarely affected by transboundary pollution due to some geographic factors.

The Philippines is an archipelago of 7000 islands characterized by complex orography and a tropical maritime climate. It belongs to the Western North Pacific (WNP) boreal summer monsoon region, which is included in the broad-scale Asian-Pacific southwest monsoon system. The southwest monsoon is active around the second half of May to September while the northeast monsoon is active around October until February. The monsoonal regimes follow the

Manuscript received October 7, 2011, revised October 10, 2011.

This work was supported in part by the Natural Sciences Research Institute (NSRI) of the University of the Philippines, Diliman, Quezon City.

Gerry Bagtasa is with the Institute of Environmental Science \& Meteorology of the University of the Philippines, Diliman Quezon City, Philippines 1101, and a research fellow of the Center for Environmental Remote Sensing of Chiba University, Chiba, Japan (September 2011 to March 2012) (e-mail: gerrybagtasa@gmail.com). seasonal migration of the Inter-tropical Convergence Zone $[4,5]$. Also, being separated from the main Asian continent by the south China sea further insulates the archipelago from atmospheric transboundary pollution. Consequently, this geographic location makes the Philippines the most susceptible to tropical cyclones forming in the western Pacific ocean.

Regional to global scale air pollution transport and dispersion is complex in nature due to the interaction of different chemical pollutants once it is emitted into the atmosphere. Air pollutants are governed by regional geography, meteorological conditions and various other mechanisms [6]. Some studies have shown the relation between meteorological factor and regional atmospheric transport. Ohara et. al. [7] showed increased urban air pollution in Japan due to transported air pollutants from the Asian continent under synoptic weather conditions. Helmis et. al. [8] estimated the inflow-outflow fluxes of $\mathrm{SO}_{2}$ and $\mathrm{NOx}$ based on the classification of synoptic-scale atmospheric characteristics, Jiang et. al. [9] found that a continuous photochemical pollution episode in Hong Kong was shown to have caused by high temperature, lower relative humidity, strong solar radiation, northerly wind and stable boundary layer.

In this study, transboundary pollution originating from East Asia was simulated during typhoon Parma on October $1-6,2009$, when it interacted with typhoon Melor via the Fujiwara effect, rendering it virtually stationary at the northern tip of the Philippines. One of this study's aims was to understand transboundary atmospheric pollution, particularly nitrogen oxides (NOx) and ozone $\left(\mathrm{O}_{3}\right)$, that can reach the Philippines with the use of the new generation air quality model WRF-CHEM version 3.2.1.

The next Section of this paper gives a brief description of the air quality transport model WRF-CHEM, meteorological data and emission inventory data used. In Section 3, the simulation results are presented and conclusion in Section 4.

\section{Model Description AND DatA}

Weather Research and Forecast (WRF) (http://www.wrf-model.org) is a mesoscale numerical weather system designed for both operational forecasting and atmospheric research applications with horizontal resolutions ranging from meters to thousands of kilometers. Is is a non-hydrostatic model, with several dynamic cores including a fully mass and scalar conserving coordinate version that is widely used in air quality prediction applications. WRF also 
includes various choices for physical parameterizations to represent processes (i.e. microphysics, cloud, radiation, etc.).

The chemistry component of the WRF-CHEM is a regional air quality modeling system, which is being continually developed by NOAA (National Oceanic and Atmospheric Administration of USA) and several other research institutes (http://ruc.noaa.gov/wrf/WG11/). The model treats the processes of transport (advective, convective and diffusive), wet and dry deposition, chemical transformation, emission, photolysis, aerosol chemistry and dynamics, etc. Detailed description of the model is found elsewhere [10]. In the past, chemical transport models treat the meteorological and chemical processes separately. Typically the meteorological model was first considered, after which a chemical model is supplied. WRF-CHEM is fully consistent with the meteorological component, having the same transport scheme, same time steps, same horizontal and vertical grids and same physical schemes for sub-grid scale transport. The simulation domain for this study includes China, Taiwan, parts of Korea and Japan, and some parts of Southeast Asia. The model run has a horizontal grid spacing resolution of $50 \mathrm{~km}$. The domain and configuration settings used in this study are summarized in table 1 .

TABLE I: WRF-CHEM DOMAIN AND CONFIGURATION SETTINGS

\begin{tabular}{ll}
\hline \hline Horizontal Dimension & 90,90 \\
(x,y) & $50 \mathrm{~km}$ \\
Grid Spacing & $120 \mathrm{~s}$ \\
Time Step & Lin et.al. \\
\hline \hline Microphysics & RRTM Scheme \\
Long-wave radiation & Dudhia \\
Short-wave radiation & Monin Obukhov Scheme \\
Surface layer & Unified Noah land surface model \\
Land Surface model & YSU Scheme \\
PBL & Kain-Fritsch \\
Cumulus parameterization & RADM2 \\
Chemistry option & Madronich \\
Photolysis &
\end{tabular}

For the simulation in this study, the meteorological initial and boundary conditions are from the National Center for Environmental Prediction (NCEP) Final Operational Model Global Tropospheric Analyses (FNL) data, available every 6 hours at $1^{0}$ x $\quad 1^{0}$ grid spacing resolution (http://dss.ucar.edu/datasets/ds083.2/).

Anthropogenic emissions for gaseous species was from the global emission inventory data for the year 2000 compiled and distributed by the Database for Global Atmospheric Research (EDGAR) system (http://www.mnp.nl/edgar) and Reanalysis of tropospheric chemical composition (RETRO) (http://retro.enes.org/index.shtml).

\section{RESUlTS AND DisCUSSION}

\section{A. Meteorological Condition}

The annual cycle of monsoonal wind pattern is shown in Figure 1. The northeast and southwest monsoon periods includes months with predominantly northeasterly and southwesterly wind flows, respectively. A transition period between northeast and southwest monsoon is marked by an easterly wind flow that starts around February and ends in May. Figure 2 on the other hand, shows a northwest wind flow pattern induced by a tropical cyclone at the northern tip of the Philippines just south of Taiwan. The slow horizontal motion of the cyclone sustained the northwesterly wind flow for several days during the first week of October 2009.

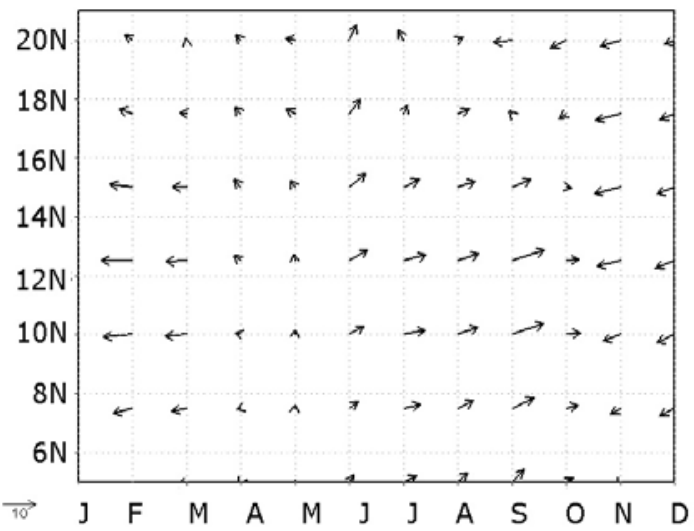

Fig. 1. Time-latitude plot of monthly mean wind vectors (ms-1) averaged from 1000 to $850 \mathrm{hPa}$ and over longitude bands between $1160 \mathrm{E}$ to $1270 \mathrm{E}$ (Source: NCEP Reanalysis data provided by NOAA/OAR/ESRL PSD, Boulder, Colorado, USA from their website at http://www.esrl.noaa.gov/psd)

\section{Wind Vector}

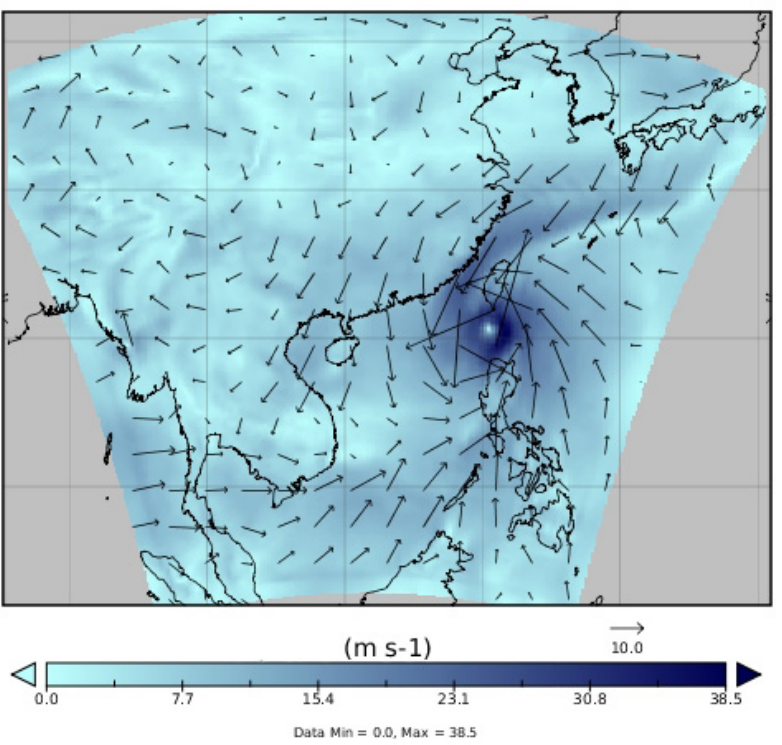

Fig. 2. Wind Field on 4 October 2009

\section{B. Transboundary Atmospheric Pollution}

Numerical simulation was performed from 00 UTC on 1 October 2009 to 24 UTC on 6 October 2009. The simulation showed that primary gaseous pollutants $\mathrm{NO}$ and $\mathrm{NO}_{2}$ were transported only for a few hundred kilometers on the Asian mainland and emissions from the southern-most part of China and Taiwan dispersed quickly over the South China Sea, far from reaching the Philippines. $\mathrm{NO}$ and $\mathrm{NO}_{2}$ emissions remained in the atmosphere for less than $9 \mathrm{hr}$ and $22 \mathrm{hr}$, respectively. Figure 3 (a) and (b) shows $\mathrm{NO}_{2}$ concentrations on 4 October 2009 at 12 UTC and 24 UTC, respectively. Since high concentration of NOx is mainly anthropogenic in nature, NOx gases are very important in studying the effects of human activities on atmospheric chemistry. 
$\mathrm{NO} 2$



no2 (ppmv)

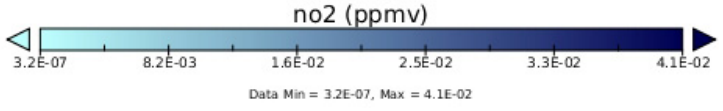

(a)

NO2
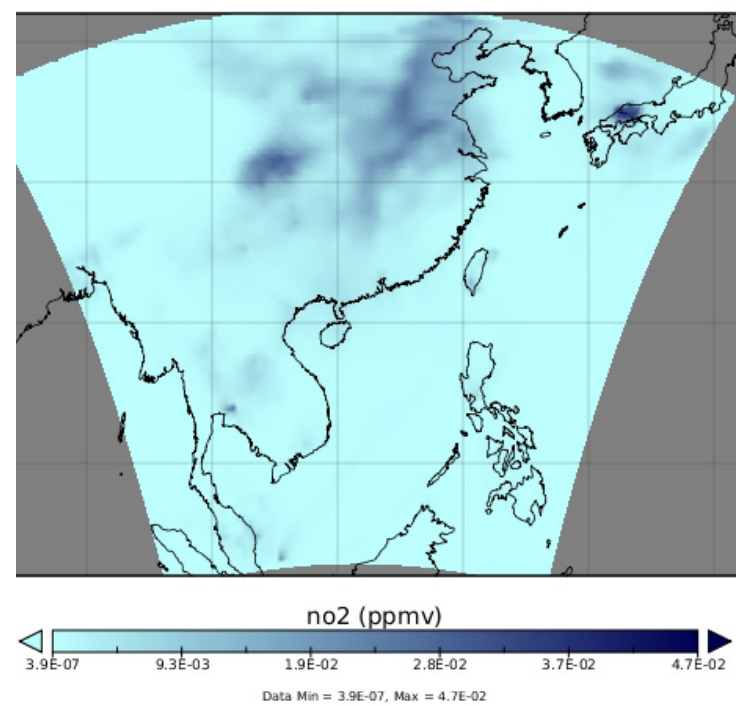

(b)

Fig. 3. Simulated NO2 concentration on 4 October 2009 at (a) 12 UTC and (b) 24 UTC.

The secondary pollutant ozone, which is a by-product of $\mathrm{NO}_{\mathrm{X}}$ emissions, was transported mainly from China to the northwestern part of the Philippines. $\mathrm{O}_{3}$ originates mainly from photochemical reaction of $\mathrm{NO}_{\mathrm{X}}$ and volatile organic compounds or VOC in the atmosphere. Besides being a greenhouse gas, tropospheric $\mathrm{O}_{3}$ also has great oxidation capacity and important health effects in the urban environment $[11,12]$. Figure 4(a), 4(b), 4(c) and 4(d) show $\mathrm{O}_{3}$ concentration in successive 6-hour interval from 06 UTC to 24 UTC of 4 October 2009.

Simulation of $\mathrm{O}_{3}$ photolysis shows maximum $\mathrm{O}_{3}$ production at approximately 04 UTC to 06 UTC or $1200 \mathrm{H}$ to $1400 \mathrm{H}$ local time and mainly in the mid and northeastern region of China. This coincides with maximum sunlight that is an essential factor in the production of tropospheric $\mathrm{O}_{3}$. On average, simulation shows up to approximately $80 \mathrm{ppbv} \mathrm{O}_{3}$ is being produced over China. $\mathrm{O}_{3}$ remained in the atmosphere for more than 24 hours and even before dispersing, a new batch of $\mathrm{O}_{3}$ is produced on the succeeding day adding to the total concentration. Tropospheric $\mathrm{O}_{3}$ takes approximately 15 hrs to reach most of the northern islands of the Philippines during the persistence of typhoon Parma, adding about 40 ppbv to local levels. Only slight increase in $\mathrm{O}_{3}$ concentration was seen for the rest of the islands.

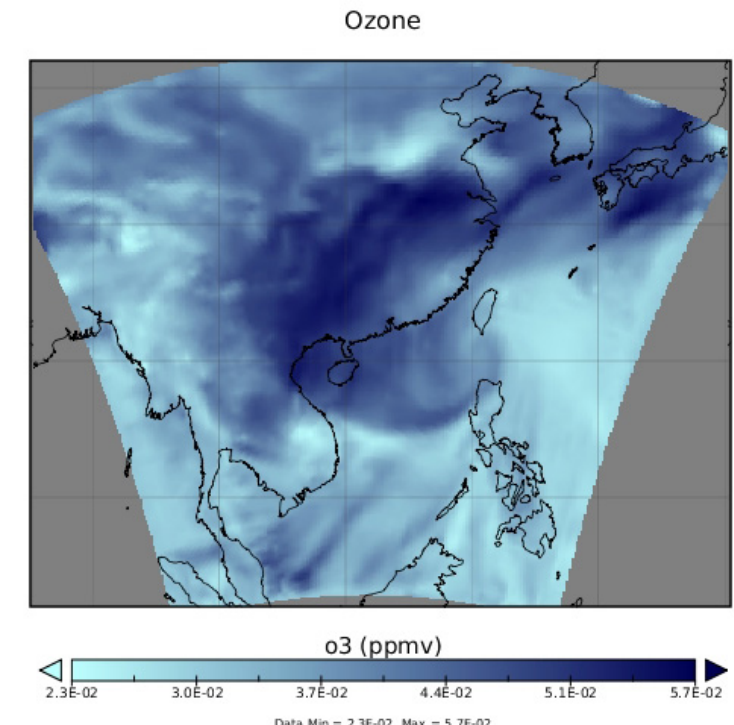

(a)

Ozone
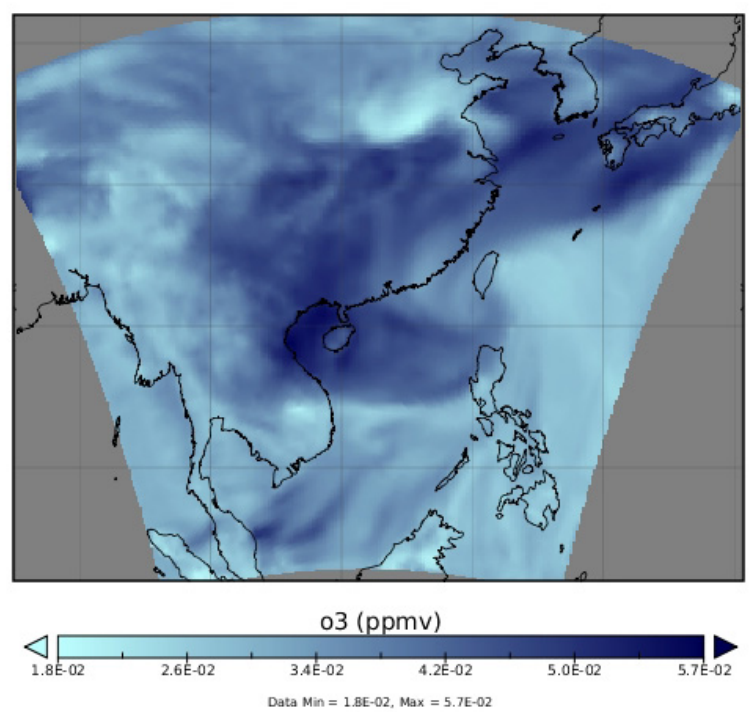

(b)

Ozone
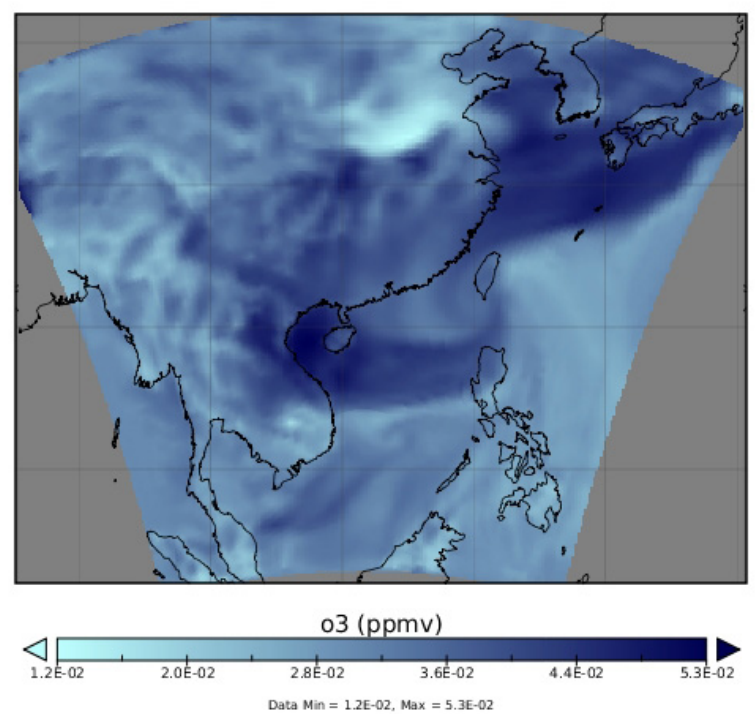

(c) 
Ozone

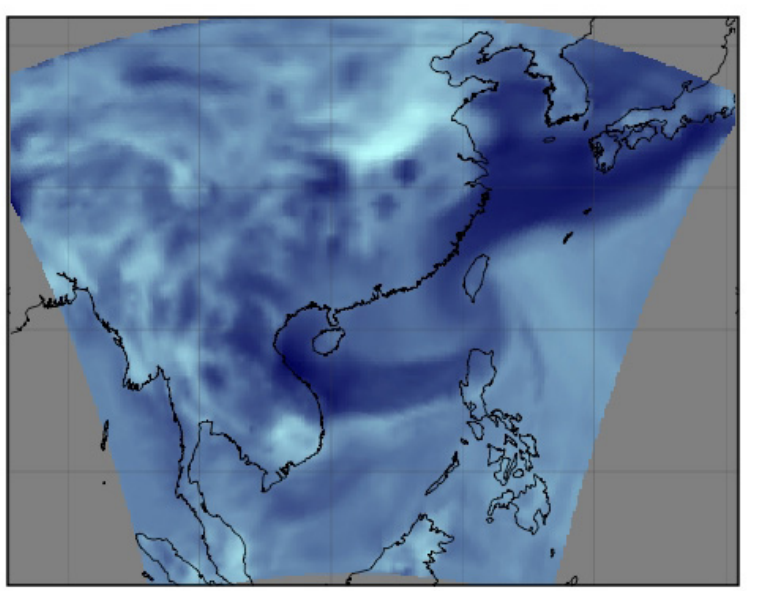

o3 (ppmv)

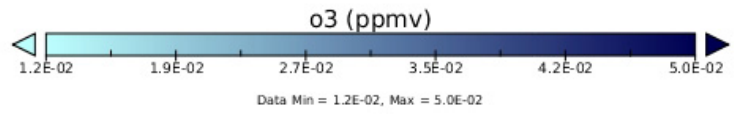

(d)

Fig. 4. Simulated Ozone concentration on 4 October 2009 at (a) 6 UTC, (b) 12 UTC, (c) 18UTC and (d) 24 UTC.

The simulation also shows relatively high $\mathrm{O}_{3}$ concentration from Japan moving towards the southwest direction to Taiwan then follows the spiral path of the typhoon.

\section{Future Outlook}

It is important to note here that emission data used in the simulation is from the year 2000. From that year to 2003, NOx emissions, which is a precursor of $\mathrm{O}_{3}$, in China had increased from $11 \mathrm{Tg} /$ year to approximately $14.5 \mathrm{Tg} /$ year [13] and is expected to further increase year to year. Future NOx emission prediction for China puts it at 39 and $128 \%$ by 2020 for the Reference Case Scenario (sustainable scenario with moderate emission rates caused by the suppression of energy consumption through energy conservation, a change to clean energy, and the moderate deployment of new energy technologies and new emission control technologies) and Policy Failure Scenario (pessimistic scenario with high emission rates caused by continuation of the current energy structure, increased energy consumption, and the slow deployment of new energy technologies and new emission control technologies), respectively [14]. The concentration values of this numerical simulation were most likely underestimated, and will only tend to increase for future instances under the same synoptic meteorological condition.

\section{CONCLUSION}

This study used a new generation numerical air quality model (WRF-CHEM) to illustrate the transboundary atmospheric pollution from East Asian countries, which are undergoing rapid economic and industrial expansion, to the Philippines. Simulation showed that concentration of some primary gaseous pollutants $\left(\mathrm{NO}\right.$ and $\mathrm{NO}_{2}$ ) dissipate over the South China sea while other atmospheric pollutants such as ozone can undergo long-range transport and affect most parts of the Philippines' northern island under certain synoptic meteorological conditions. Future increase in emission, particularly in China, can have more impact in the air quality of the Philippines and the rest of Asia.

\section{ACKNOWLEDGMENT}

The author would like to acknowledge the CISL Research Data Archive (http://dss.ucar.edu) for their wonderful archive of meteorological reanalysis data. And to the Reanalysis of tropospheric chemical composition (RETRO) (http://retro.enes.org/index.shtml) and Database for Global Atmospheric Research (EDGAR) system (http://www.mnp.nl/edgar) emission inventory databases.

\section{REFERENCES}

[1] M. Lin, T. Holloway, G. R. Carmichael, and A. M. Fiore, "Quantifying pollution inflow and outflow over East Asia in spring with regional and global models," Atmos. Chem. Phys., 10, 4221-4239, 2010

[2] Akimoto, H., "Global air quality and pollution," Science, 302, 1716-1719, 2003.

[3] M. Fang, C.K. Chan, X.M. Yao, "Managing air quality in a rapidly developing nation: China," Atmospheric Environment 43, 79-86, 2009.

[4] C.P. Chang, "The Maritime Continent Monsoon". presented at the report of the International Committee of the Third International Workshop on Monsoons (IWM-III) entitled, "The Global Monsoon System: Research and Forecast," Huangzou, China, November 2004

[5] D.E. Waliser, "Tropical Meteorology: Intertropical Convergence Zones (ITCZ)," Encyclopedia of Atmospheric Sciences 2002. Edited by J. Holton, J. Pyle, J. Curry. Academic Press.

[6] D.S. Chen, S.Y. Cheng, L. Liu, T. Chen, X.R. Guo, “An integrated MM5-CMAQ modeling approach for assessing trans-boundary PM10 contribution to the host city of 2008 Olympic summer games in Beijing, China," Atmospheric Environment 41, 1237-1250, 2007.

[7] T. Ohara, Toshimasa, I. Uno, S. Wakamatsu, K. Murano, "Numerical Simulation of the Springtime Trans-Boundary Air Pollution in East Asia," Water, Air, \& Soil Pollution, 130, 295-300, 2001.

[8] C.G. Helmis, N. Moussiopoulus, H.A. Flocas, P. Sahm, V.D. Assimakopoulus, C. Naneris and P. Maheras, "Estimation of Transbounary Air Pollution on the basis of Synoptic scale Weather Types," International Journal on Climatology 23, 405-416, 2003.

[9] F. Jiang, T. Wang, T. Wang, M. Xie, H. Zhao. "Numerical modeling of a continuous photochemical pollution episode in Hong Kong using WRF-chem.," Atmospheric Environment 42 8717-8727, 2008.

[10] G.A. Grell, S.E. Peckham, R. Schmitz, S.A. McKeen, G. Frost, W.C. Skamarock, B. Eder. "Fully coupled "online", chemistry within the WRF model," Atmospheric Environment, 39, 6957-6975, 2005.

[11] J.A. Logan, M.J. Prather, S.C. Wofsy, and M.B. McElroy, "Tropospheric chemistry: a global perspective," J.Geophys. Res., 86, 7210-7254, 1981.

[12] National Research Council (NRC), "Rethinking the Ozone Problem in Urban and Regional Air Pollution," Nat. Acad. Press, Washington, D.C., 1991.

[13] P.S. Monks, C. Granier, S. Fuzzi, A. Stohl, M.L. Williams, H. Akimoto, M. Amann, A. Baklanov, U. Baltensperger, I. Bey, N. Blake, R.S. Blake, K. Carslaw, O.R. Cooper, F. Dentener, D. Fowler, E. Fragkou, G.J. Frost, S. Generoso, P. Ginoux, V. Grewe, A. Guenther, H.C. Hansson, S. Henne, J. Hjorth,, A. Hofzumahaus, H. Huntrieser, I.S. Isaksen, M.E. Jenkin, J. Kaiser, M. Kanakidou, Z. Klimont, M. Kulmala, P. Laj, M.G. Lawrence, J.D. Lee, C. Liousse, M. Maione, G. McFiggans, A. Metzger, A. Mieville, N. Moussiopoulos, J.J. Orlando, C.D. O'Dowd, P.I. Palmer, D.D. Parrish, A. Petzold, U. Platt, U. Poschl, A.S. Prevot, C.E. Reeves, S. Reimann, Y. Rudich, K. Sellegri, R. Steinbrecher, D. Simpson, H. ten Brink, J. Theloke, G.R. van der Werf, R. Vautard, V. Vestreng, C. Vlachokostas, R. von Glasow. "Atmospheric composition change -- Global and regional air quality". Atmospheric Environment, 43, 5268-5350, 2009.

[14] T. Ohara, H. Akimoto, J. Kurokawa, N. Horii, K. Yamaji, X. Yan, and T. Hayasaka, "An Asian emission inventory of anthropogenic emission sources for the period 1980-2020," Atmos. Chem. Phys., 7, 4419-4444, 2007. 